\title{
Täuschung durch Christus? \\ Die biblische Emmausperikope als Herausforderung mittelalterlicher Offenbarungstheologie
}

\section{THOMAS MARSCHLER}

\section{Die augustinische Vorgabe}

Zu den zahlreichen prägenden Einflüssen, die Augustinus auf die Theologie des Mittelalters ausgeübt hat, zählt auch die Bewertung der Lüge. Vor allem in den beiden unmittelbar dieser Thematik gewidmeten Schriften ,De mendacio' (verfasst um 395, kurz vor Augustins Bischofsweihe) und ,Contra mendacium' (entstanden um 420), ${ }^{1}$ die ,,als solche im gesamten Schrifttum der heidnischen wie der christlichen Antike einzig dastehen", 2 ist das Ringen des Kirchenvaters um die klare ethische Beurteilung der Lüge, eine Aufzählung ihrer verschiedenen Arten und die Abgrenzung zu Formen des Irrtums und erlaubter Verstellung greifbar. Die in der lebenslangen Auseinandersetzung Augustins am Ende herausgeformte Position, wie sie in ,Contra mendacium ' dokumentiert ist, hat nicht nur die vielfältige Diskussion der Lüge in der antiken heidnischen Philosophie und Rhetorik, ${ }^{3}$ sondern auch die ebenfalls noch keineswegs einstimmige Behandlung des Lügenthemas in der vorangehenden christlichen Erörterung beendet und ist für die Theologie der Folgezeit, wenigstens bis ins 20. Jahrhundert hinein, zum kaum mehr bestrittenen Maßstab geworden.

Grundsätzlich gehört das Verbot der Lüge und die korrespondierende Verpflichtung zu uneingeschränkter Wahrhaftigkeit zum sittlichen Grundbestand der biblischen Religion von Juden und Christen. ${ }^{4}$ Diese Erkenntnis ist in der theologischen Reflexion des überlieferten Bekenntnisses von Anfang an unbestritten. Fragen erheben sich allerdings im Blick auf mögliche Ausnahmen und Grenzfälle. Sie werden genährt durch zahlreiche Stellen in der Heiligen Schrift selbst, die zu berichten scheinen, dass heilige Personen oder sogar Gott selbst bewusst jenen Unterschied zwischen äußerer Rede bzw. Handlung und innerem Wissen zum Einsatz bringen, durch den gewöhnlich „Lüge“ definiert wird. Zur Debatte steht damit das Problem einer möglichen teleologischen Rechtfertigung der Lüge, die Frage also, ob durch die Verfolgung einer bestimmten guten Intention gewisse Falschaussagen oder Verstellungen ethisch akzeptabel werden. Während in der östlichen Vätertheologie, wohl unter dem Einfluss Platos, vor allem Clemens von Alexandrien und Origenes die Lüge in Einzelfällen als erlaubtes Instrument angesehen haben und während die östliche Spiritualität Beispiele der Lüge aus Liebe oder Demut kennt und auch in der generell strengeren westli-

1 Zur bibliographischen Erstorientierung vgl. Wilhelm Geerlings, Augustinus - Leben und Werk. Eine bibliographische Einführung. Paderborn u. a. 2002, S. 191, 203; Boniface Ramsey, ,De mendacio\%,Contra mendacium . In: Allan D. Fitzgerald (Hg.), Augustine through the ages. An encyclopedia. Grand Rapids, Cambridge 1999, S. 555-556.

2 Paul Keseling, Einführung zu: Aurelius Augustinus, Die Lüge und Gegen die Lüge. Würzburg 1953, S. XXIX.

3 Roger D. Ray, Christian conscience and pagan rhetoric. Augustine's treatises in lying. Studia Patristica 22 (1987), S. 321-325.

4 Hans Conzelmann, pseudos. In: Theologisches Wörterbuch zum Neuen Testament. Bd. 9 (1973), S. 590-599 (mit Literaturangaben). 
chen Tradition Autoren wie Hilarius von Poitiers oder Hieronymus ein gewisses Schwanken in der Frage zeigen, ob um des eigenen oder fremden Heiles willen eine zeitweise Verstellung gerechtfertigt ist, ${ }^{5}$ kommt Augustinus zu einem eindeutig negativen Urteil. ${ }^{6}$ Lüge als Verletzung des hohen Gutes der Wahrheit ist unter keinen Umständen erlaubt. Sie zerstört das Zusammenleben der Menschen und verletzt die Würde des auf Wahrheitserkenntnis ausgerichteten geistigen Geschöpfes, ja Gottes selbst als der erhabenen Erstwahrheit. ${ }^{7}$ Sogar gegenüber Irrlehrern, die wie die in ,Contra mendacium' bekämpften Priscillianisten zum Kampfmittel der Lüge greifen, darf der Katholik seinerseits nicht mit Berufung auf die eigene gute Absicht zum Lügner werden. Dieses Mittel anzuwenden wäre ebenso irrig wie ein Versuch, Ehebrecher durch Ehebruch oder Mörder durch Mord aufspüren zu wollen. ${ }^{8}$

Auf dem Hintergrund dieser Position wird die Klärung der scheinbar für die Erlaubtheit der Lüge sprechenden Schriftstellen für Augustinus um so dringlicher. Paradigmatisch ist seine Deutung von Gal 2, 11-14 mit der Frage, ob der dort berichtete Konflikt zwischen Petrus und Paulus nichts anderes war als ein abgesprochenes Scheingefecht. Der sich an dieser Stelle entzündende Auslegungsstreit zwischen Augustinus und Hieronymus hat die Forschung schon länger lebhaft interessiert. ${ }^{9}$ Weite Passagen sowohl in ,De mendacio' als auch in ,Contra mendacium“ hat Augustinus dem Versuch gewidmet, Missverständnisse in der Deutung von Weisungen der Schrift oder in ihr berichteten Handlungen zu klären und Widersprüche zwischen Worten und Taten biblischer Personen durch genaue Bestimmung des Wortsinns auszuräumen. ${ }^{10}$ Scheinbare Lügen in der Offenbarungsgeschichte erweisen sich, sofern sie nicht als schlichte Fehlinterpretationen des biblischen Textes enttarnt werden können, in der Interpretation des Augustinus als affektbestimmte Urteilsverwirrung, als gerechtfertigtes Verschweigen der Wahrheit ohne Falschaussage oder als ebenso untadelige fi-

5 Vgl. Boniface Ramsey, Two traditions on lying and deception in the ancient church. The Thomist 49 (1985) S. 504-533; Gregor Müller, Die Wahrhaftigkeitspflicht und die Problematik der Lüge. Ein Längsschnitt durch die Moraltheologie und Ethik unter besonderer Berücksichtigung der Tugendlehre des Thomas von Aquin und der modernen Lösungsversuche (Freiburger theologische Studien 78). Freiburg, Basel, Wien 1962, S. 49-77; Franz Schindler, Die Lüge in der patristischen Literatur. In: Albert M. Koeniger (Hg.), Beiträge zur Geschichte des christlichen Altertums. Fschr. Albert Ehrhard. Bonn, Leipzig 1922, S. 421-433; Emil Dorsch, Die Wahrheit der biblischen Geschichte in den Anschauungen der alten christlichen Kirche. Zeitschrift für katholische Theologie 29 (1905) S. 631-653; 30 (1906) S. 57-107, 227-265, 430-453, 671-692; 31 (1907) S. 86-101, 229266. Die letztgenannte Arbeit ist materialreich, jedoch stark vom Streit um die Exegese in der katholischen Modemismuskrise ihrer Entstehungszeit geprägt.

6 Überblick bei Bernard Roland-Gosselin, La morale de saint Augustin. Paris 1925, S. 127-141; Müller [Anm. 5], S. 64-76; Thomas Feehan, Augustine on lying and deception. Augustinian Studies 19 (1988) S. 131-139; ders., The morality of lying in St. Augustine. Augustinian Studies 21 (1990) S. 67-81; ders., Augustine's own examples of lying. Augustinian Studies 22 (1991) S. 165-190. Viele Hinweise zu Augustinus und seiner Nachwirkung finden sich auch bei Gillian R. Evans, Getting it wrong. The medieval epistemology of error (Studien und Texte zur Geistesgeschichte des Mittelalters 63). Leiden u. a. 1998, S. 181-204 (,Truth and lies*).

7 Ramsey [Anm. 5], S. $511 \mathrm{f}$.

8 Augustinus, ,Contra mendacium', 41, in: Corpus Scriptorum Ecclestiasticorum Latinorum [im Folgenden CSEL], Bd. 41, S. 528.

9 Ralph Hennings, Der Briefwechsel zwischen Augustinus und Hieronymus und ihr Streit um den Kanon des Alten Testaments und die Auslegung von Gal. 2, 11-14 (Vigiliae Christianae 21). Leiden, New York, Köln 1994, S. 121-130, 249-264; Ulrich Wilckens u. Alois Kehl, Heuchelei. B. Christlich. In: Reallexikon für Antike und Christentum. Bd. 14 (1988), S. 1215-1231; Ronald S. Cole-Turner, Anti-heretical issues and the debate over Galatians 2:11-14 in the letters of St. Augustine to St. Jerome. Augustinian Studies 11 (1980), S. $155-160$.

10 ,De mendacio', 26-41 (CSEL 41, S. 446-463); ,Contra mendacium', 13-16, 19-33 (CSEL 41, S. 485-516, 491-495). 
gürliche Darstellung bzw. symbolische Prophetie. " Wo (vor allem im Alten Testament) von echten Lügen berichtet wird, sind sie als solche niemals zur Nachahmung bestimmt. ${ }^{12}$ Als generelle Auslegungsregel Augustins darf dabei seine resümierende Feststellung in ,Contra mendacium“, n. 35, gelten: „Entweder zeigt man, daß die vermeintliche Lüge gar keine ist [...], oder man weist nach, daß ausgemachte Lügen nicht nachgeahmt werden dürfen, und sind uns solche wie andere Sünden unterlaufen, daß man ihnen dann nicht den Wert sittlicher Handlungen zuschreiben, sondern für sie um Verzeihung nachsuchen muß““.13

Um diese hermeneutischen Feststellungen zu konkretisieren und ihr Fortwirken im Mittelalter aufzuzeigen, ist es sinnvoll, eines jener von Augustinus interpretierten Exempla für scheinbare Täuschung in der Bibel herauszugreifen. Die Emmausperikope eignet sich als Beispiel in besonderem Maße, denn sie enthält gleich zwei Aspekte, die in Probleme mit dem Anspruch auf unbedingte Wahrhaftigkeit für das Handeln Christi zu führen scheinen. Beiden hat sich Augustinus in seinem Werk zugewandt.

a) Das erste erklärungsbedürftige Faktum betrifft die Tatsache, dass sich Christus den beiden Jüngern als ein Weggefährte zugesellt hat, der offenbar in seiner wahren Identität nicht sofort zu erkennen war. Bis zum Brotbrechen waren die Augen der Jünger nach den Worten des Evangelisten „gehalten, so dass sie ihn nicht erkannten“ (Lk 24, 16). In ,De consensu euangelistarum' (um 400) gesteht Augustinus zu, dass diese Behinderung von Gott selbst zugelassen wurde „um eines bestimmten Geheimnisses willen“ (certi mysterii cau$s a) .{ }^{14}$ Die Verdunklung in den Augen der Jünger stellte nichts anderes dar als eine Entsprechung zum Zustand ihres Geistes, der noch in Unwissenheit über Tod und Auferstehung Christi befangen war. ${ }^{15}$ Zugleich sollte zum Ausdruck gebracht werden, dass Christus nur erkennen kann, wer mit der Kirche in der Einheit des eucharistischen Brotbrechens steht. ${ }^{16}$ Bei Augustinus finden sich an der genannten Stelle auch schon beginnende Spekulationen über die Verursachung des den Jüngern zeitweise auferlegten impedimentum bei der Erkenntnis der wahren Gestalt Christi: Die Unfähigkeit, Gesehenes zu erkennen, kann durch die Anwesenheit irgendeiner ,Dunkelheit“ oder eines ,,(Körper-)Saftes“ bedingt sein. ${ }^{17}$ Als Urheber dieser Verwirrung darf man nach Augustinus den Teufel in Betracht ziehen, jedoch nur unter der Voraussetzung einer entsprechenden Zulassung Christi. Dass der Herr selbst sein Aussehen so verändert haben könnte, dass er für die Jünger unerkennbar wurde, wird dagegen zwar nicht prinzipiell (als Möglichkeit des Auferstehungsleibes, die anderswo durchaus zum Einsatz kam), wohl aber im konkreten Fall ausgeschlossen.

\footnotetext{
,Contra mendacium`24, 27 (CSEL 41, S. 499-502, 507f.)

Ebd. 30, 32-34, S. 510f., 512-518.

CSEL 41, S. 518 f. Übersetzung nach Keseling [Anm. 2], S. 114.

Augustinus, ,De consensu euangelistarum', 3, 72 (CSEL 43, S. 373).

5 Dieser Gedanke begegnet bei Augustinus auch in ,Enarrationes in Psalmos' 68, 1, 8 (Corpus Christianorum, Series Latina [im Folgenden CCL] 39, S. 909): quomodo enim oculis agnoscerent, a quo mente titubarant? factum erat aliquid in oculis eorum simile mentis ipsorum. Vgl. weiterhin, Sermones‘ 236, 2 (Patrologia Latina [im Folgenden PL] 38, Sp. 1121); ,Sermones‘ 239, 2 (PL 38, Sp. 1128).

16 Auf die eucharistische Brotbrechung wird die Mahlszene der Emmausperikope auch in einer Predigt Augustins gedeutet: ,Sermones“ 234, 2 (PL 38, Sp. 1116).

17 Augustinus, ,De consensu euangelistarum', 3, 72 (CSEL 43, S. 373): sed inerat aliquid quo non sinerentur agnoscere quod uidebant, quod scilicet et caligo et aliquis umor efficere solet.
} 
b) Ein weiteres Problem wirft für den Interpreten der Emmausperikope der Vers Lk 24, 28 auf: Der auferstandene Herr, der den beiden Jüngern auf dem Weg begegnet ist, „tat so, als wollte er weitergehen“. ${ }^{18}$ Das in der Vulgata hier gebrauchte Prädikat fingere ist als solches schon ein Reizwort für den, der in der Schrift ungetrübte Wahrheit sucht. Augustinus behandelt die Stelle am ausführlichsten in ,Contra mendacium', n. 28. Ihm geht es dort vor allem darum, die Berufung der Priscillianisten auf die erwähnte fictio als irrig zu erweisen. Dazu greift er auf die Interpretation des Geschehens als Gleichnis, als symbolisch zu verstehendes Mysterium zurück. Schon in seinen ,Quaestiones euangelii' (entstanden um 400) hatte Augustinus eine solche ,bedeutungsvolle" Fiktion mit Bezug auf unsere Perikope von „leerer“" Täuschung unterschieden. ${ }^{19}$ Was sich als Stilmittel bereits bei profanen Dichtern, in den Satiren des Horaz oder den Fabeln des Äsop, findet, gibt es als uneigentliche, übertragene Rede auch in der Heiligen Schrift. Christus nun stellt sich nach Augustinus gegenüber den Emmausjüngern so, als wollte er sie verlassen, um zeichenhaft sein endgültiges Fortgehen in der Himmelfahrt vorwegzunehmen, das ebenfalls kein Zurücklassen der Jünger schlechthin war, da er ihnen im Hl. Geist nahe blieb. ${ }^{20}$ Wer Christus in seinem Verhalten gegenüber den Jüngern Lüge vorwerfen wollte, könnte dies nur, wenn er zugleich die spätere Erfüllung des hier vorbildhaft bezeichneten Geheimnisses leugnete. Der in einer früheren Abhandlung in die Deutung einfließende Gedanke, der Herr habe den Jüngern mit seiner fictio die Gelegenheit eingeräumt, an ihm die Tugend der Gastfreundschaft (hospitalitas) zu beweisen, um darüber zur Erkenntnis seiner Person zu gelangen, ${ }^{2 !}$ wird in der Spätschrift ,Gegen die Lüge" nicht mehr aufgegriffen.

\section{Die Emmausperikope in der theologischen Deutung des 12. und 13. Jahrhunderts}

In der Deutung der mittelalterlichen Theologen kehrt die negative Intention in der Auslegung Augustins durchgängig wieder: Das Verhalten Christi war keine sündhafte Täuschung oder Rechtfertigung menschlicher Lüge, sondern geistlich zu deutendes Medium eines höheren Sinns. In der positiven Herausarbeitung dieses Sinns findet sich allerdings eine interes-

Zum Folgenden auch Thomas Marschler, Auferstehung und Himmelfahrt Christi in der scholastischen Theologie bis zu Thomas von Aquin (Beiträge zur Geschichte der Philosophie und Theologie des Mittelalters, Neue Folge 64 I/II). Münster 2003, Bd. 1, S. 485-488.

19 Augustinus, ,Quaestiones euangeliorum $2,51,1$ (CCL 44B, S. 117): non etiam omne quod fingimus mendacium est; sed quando id fingimus quod nihil significat, tunc est mendacium. cum autem fictio nostra refertur ad aliquam significationem, non est mendacium sed aliqua figura ueritatis.

Augustinus lehnt die These ab, quasi mendacium sit omne quod fingitur, cum ueraciter aliud ex alio significandi causa tam multa fingantur. si ergo nihil aliud significasset lesus in eo, quod longius ire se finxit, merito iudicaretur esse mendacium. porro autem si bene intellegatur et ad id, quod uoluit significare, referatur, inuenitur esse mysterium. alioquin erunt cuncta mendacia, quae propter quandam rerum significandarum similitudinem, cum gesta non sint, tamquam gesta narrantur. [...] haec dixi propter id, quod scriptum est de Iesu: ,et ipse se finxit longius ire', ne quisquam ex hoc uerbo, sicut Priscillianistae, licitum uolens habere mendacium insuper etiam Christum contendat fuisse mentitum. quisquis autem uult intellegere illud fingendo quid praefigurauerit, adtendat, quid agendo perfecerit. longius namque postea profectus super omnes caelos non tamen deseruit discipulos suos. propter hoc significandum futurum diuinitus factum ad praesens illud est humanitus fictum. et ideo significatio uerax in illa est fictione praemissa, quia in hac profectione illius est significationis ueritas subsecuta. ille igitur contendat Christum mentitum esse fingendo, qui negat eum quod significauit impleuisse faciendo: , Contra mendacium', c. 28 (CSEL 41, S. 510).

21 Augustinus, ,Quaestiones euangeliorum‘ 2,51,2 (CCL 44B, S. 509); ähnlich auch Augustinus, ,Sermones‘ 89, 7 (PL 38, Sp. 559). 
sante Bandbreite der Thesen, welche immer wieder die bei Augustinus zu findenden Vorgaben nutzbar machen, jedoch auch über sie hinausgehen. Indem sich die Scholastiker sowohl im Kontext der unmittelbaren Schriftkommentierung wie auch in systematischen Kontexten, vor allem in Traktaten zur Auferstehung Christi und zur Eucharistie, dem Emmausgeschehen nach beiden oben aufgezeigten Problemaspekten zuwenden, greifen sie auf unterschiedliche Quellen patristischen Materials zurück und bringen zugleich eigene Fragerichtungen und Erklärungsvarianten zur Sprache, die wir im Folgenden zu identifizieren suchen. Wir beschränken uns dabei auf den repräsentativen Zeitraum von der Frühscholastik des 12. Jahrhunderts bis zu Thomas von Aquin ( $†$ 1277).

\subsection{Initiative Christi oder Schuld der Jünger? (Frühscholastik)}

Einen ersten Lösungsversuch hält schon Robertus Pullus $(\dagger 1146)$ bereit: ${ }^{22}$ Absit a fide praestigium - eine Täuschung (delusio) durch Christus ist undenkbar. Im Hintergrund steht wohl Augustins Differenzierung zwischen fictio und mendacium, die sich zu Beginn von ,De mendacio' findet. ${ }^{23}$ Lüge, so hatte Augustinus dort gelehrt, setzt auf jeden Fall eine böse Absicht des Handelnden bzw. Sprechenden voraus. ${ }^{24}$ Der Scholastiker lenkt prinzipiell in die Erklärungslinie des Augustinus ein, wenn er ausführt, dass Christus mit seiner Erscheinung vor den Jüngern ein positives pädagogisches Ziel verfolgt hat. ${ }^{25}$ Christus hat, wie Pullus mit Augustinus feststellt, keine fremde species angenommen, sondern sich höchstens in einer fremden gezeigt. Er verbirgt seine Herrlichkeitsgestalt, weil diese die Jünger erschrekken würde. Etwas Analoges vollzieht sich, wann immer wir den Herrn im Altarsakrament empfangen. ${ }^{26}$ Im selben Kontext erklärt auch Petrus Lombardus $(\dagger 1160)$ die Emmausperikope zum Paradigma einer ,sakramental“"-verdeckten Wahrheitsvermittlung, die nicht als Betrug abzuqualifizieren ist. ${ }^{27}$ Der Porretaner Radulfus Ardens ( $\dagger$ ca. 1200) vergleicht das Verhalten Christi mit dem eines Lehrers, der vor seinen Schülern so tut, als sei er zornig, um bei ihnen Furcht zu erzeugen und damit den Lernerfolg zu steigern. Wenn also der Herr vorgab, weitergehen zu wollen, so verfolgte er nur das Ziel, die Liebe der beiden Jünger zu erproben. ${ }^{28}$ Der Pariser Lehrer Petrus Cantor $(\dagger 1197)$ macht sich bereits konkrete Gedanken

22 Robertus Pullus, ,Sententiae' 5, 1 (PL 186, Sp. 829D-830C).

${ }^{23}$ Augustinus, ,Quaestiones euangeliorum‘ 2, 51, 1 (CCL 44B, S. 117). Zur Unterscheidung auch Maria A. Sánchez Manzano, La expresión de la falsedad y del error en el vocabulario agustiniano de la mentira. Augustinus 34 (1989), S. 267-279.

24 Augustinus, ,De mendacio“ I, 1 (CSEL 41, S. 413). Vgl. Evans [Anm. 6], S. $193 \mathrm{f}$.

25 Augustinus, ,Contra mendacium' (CSEL 41, S. 64).

26 Vgl. auch Magister Martinus, Cod. Paris Nat. lat. 14526, f. 139rb, ediert in: Richard Heinzmann, Die Unsterblichkeit der Seele und die Auferstehung des Leibes. Eine problemgeschichtliche Untersuchung der frühscholastischen Sentenzen- und Summenliteratur von Anselm von Laon bis Wilhelm von Auxerre (Beiträge zur Geschichte der Philosophie und Theologie des Mittelalters 40). Münster 1965, S. 185 (verdeckte Herrlichkeit).

27 Petrus Lombardus, Sententiae. Hrsg. v. Collegium S. Bonaventurae (Spicilegium Bonaventurianum 5). Grottaferrata 1981, 4, 12, 2, S. 304f.: nec illusio est, quia ad utilitatem fidei, non ad deceptionem ita fit; sicut et Christus se ostendit duobus discipulis in via in specie peregrini, nec in eo tamen talis forma erat, sed oculi eorum tenebantur, ne eum agnoscerent [Luc 24, 16]. Auch andere Autoren der Zeit kommen auf die Emmausperikope im Kontext des Eucharistietraktats zu sprechen; vgl. etwa: Summa Zwettlensis. Die Zwettler Summe, Einleitung und Text. Hrsg. v. Nikolaus M. Häring (Beiträge zur Geschichte der Philosophie und Theologie des Mittelalters, NF 15). Münster 1977, n. 191, S. 175; Gaufried von Poitiers, ,Summa', Cod. Paris Nat. lat. 3143 , f. $113 \mathrm{vb}$ (ediert bei Heinzmann [Anm. 26], S. 232).

28 Radulfus Ardens, ,Homiliae de tempore' 53 (PL 155, Sp. 1860A-B): Non miremini, fratres mei, quod Dominus se longius iturum finxit, quoniam non omnis fictio habet in se malitiam duplicitatis. Est enim quaedam fic- 
zum Modus, in dem dieses Erscheinen stattgefunden haben könnte, und denkt an einen Vergleich mit den „uneigentlichen Akzidenzien“ der vorösterlichen Verklärung, die vielleicht "in der Luft" erzeugt wurden. ${ }^{29}$

Allerdings bleibt die Diskussion dabei nicht stehen. Der frühe Lombardusschüler Petrus Comestor $(\dagger 1187)$ möchte nicht ausschließen, dass die Veränderung im Erscheinungsbild Christi notwendige Konsequenz der vorangegangenen Verherrlichung gewesen sein könnte: Der Herr ist als derselbe doch irgendwie ein "Anderer“ geworden, wie wir es schon bei Menschen feststellen, die wir als Erwachsene wiedertreffen, nachdem wir sie zuletzt als Kind gesehen haben. ${ }^{30}$ Damit wird zwar ein Beispiel des Augustinus aufgegriffen, ${ }^{31}$ das jedoch für die Emmausperikope eine vom Kirchenvater ausdrücklich abgelehnte Deutungsoption zur Konsequenz hat.

Bei weiteren Summisten am Ausgang der Frühscholastik verstärkt sich die Tendenz, das Nichterkennen im Sinne einer Schuld ganz auf die Seite der Jünger zu verschieben. Dabei kann man erneut auf einen Begriff der augustinischen Exegese zurückgreifen, den der Bischof von Hippo allerdings selbst nicht im Zusammenhang mit der Emmausperikope entwickelt hatte: ${ }^{32}$ Dass die Jünger den Herrn zunächst nicht erkannten, wird als Folge ihrer aurisia (eine Latinisierung des griechischen Wortes aorasia) gedeutet, ${ }^{33}$ jener Blindheit, die objektiv Gegenwärtiges nicht wahrzunehmen vermag. ${ }^{34}$ Schon hier treffen wir auf die durch Gregor den Großen ${ }^{35}$ inspirierte Formel, die der Sache nach mit einer oben zitierten Aussage

tio mala, et est quaedam fictio bona. Est [PL: Et] quaedam fictio ad decipiendum, qua inimicus se fingit amicum, ut magis decipiat. Est quaedam fictio ad erudiendum sive probandum, qua magister se fingit iratum discipulis, ut eos timere ac magis proficere faciat. [...] Nam Dominus se fingit longius iturum ut probaret caritatem discipulorum.

29 Petrus Cantor, ,Summa de sacramentis‘, 1 : ,De Eucharistia‘, $§ 65$ : ,Summa de sacramentis et animae consiliis‘. Hrsg. v. Jean-Albert Dugauquier. Bd. 1 (Analecta Mediaevalia Namurcensia 4). Louvain, Lille 1954, S. $168-170$.

30 Petrus Comestor, ,Historia scholastica. In Evangelia“, c. 191 (PL 198, S. 1639): Ibat autem Iesus cum illis et oculi eorum tenebantur, ne eum agnoscerent, unde videtur aliud in oculis eorum fuisse, ne eum agnoscerent. Et alibi legitur quod apparuit eis in aliena effigie, ergo aliud etiam erat in eo, ne eum agnoscerent. Potuit etiam esse, ut mutatio eiusdem corporis mortalis in immortale, non possit fieri sine quadam alteratione, pro qua subito visus non agnosceretur, ut, si quis quem vidisset puerum si paulo post occurentem sibi iuvenem videret, non mox eum cognosceret.

31 Augustinus, ,Epistulae' 149, 31 (CSEL 44, S. 378).

32 Magistri Guillelmi Altissiodorensis ,Summa aurea', Bd. 4. Hrsg. v. Jean Ribaillier (Spicilegium Bonaventurianum 20). Paris, Rom 1987, S. 489, Anm. zu Zeile $75 f$.

33 Vgl. Stephan Langton, ,Summa', Cod. Cambridge, St. John's C7 (James 57), f. 325rb, verbessert nach Paris Nat. lat. 14556, ediert bei: Sten Ebbesen u. Lars B. Mortensen, A partial edition of Stephan Langton's ,Summa' and ,Quaestiones' with parallels from Andrew Sunesen's ,Hexaemeron'. Cahiers de l'Institut du moyenâge grec et latin [de l'] Université de Copenhague 49 (1985), S. 25-224, hier S. 175: Oculi autem duorum discipulorum ideo tenebantur ne eum agnoscerent, quia aurisia erant percussi (sicut oculi Syrorum quaerentium Helisaeum), qua amota cognoverunt eum in fractione panis videndo eam formam quam prius viderant non agnoscendo, et ideo dicitur quod oculi tenebantur ne eum agnoscerent.

34 Alanus ab Insulis, ,Contra haereticos', I. I, c. 58 (PL 210, Sp. 362A): Sunt enim multae species fallaciae visus: Una est, quando non videmus quod oculis praesentatur, quae dicitur aurisia, id est avidentia, qua percussi fuerunt qui Elisaeum quaerebant [IV Reg. 6].

35 Talem se exhibuit Dominus in corpore, qualis apud illos erat in mente: Gregor d. Gr., ,Homiliae in evangelia“ 23, n. 1 (PL 76, Sp. 1182B-C; auch hrsg. v. Raymond Étaix [Corpus Christianorum, Continuatio Mediaevalis 141], S. 194). Vgl. zum Zitatnachweis Ribaillier [Anm. 32], S. 487, Anm. zu Zeile 21 f. 
des Augustinus ${ }^{36}$ identisch ist: Was Christus den Jüngern äußerlich darbot, war nichts anderes als das, was sie selbst in ihrem Innern prägte, nämlich Unsicherheit und Zweifel. ${ }^{37} \mathrm{Ob}$ das dabei Gesehene ein verhüllendes Luftgespinst (forma assumpta ex aëre) oder die nicht richtig erkannte wahre Gestalt war, wird weiter regelmäßig diskutiert, aber unterschiedlich beurteilt. $^{38}$ Diese drei Erklärungsstrategien - pädagogisch gerechtfertigte „Täuschung“ durch Christus selbst; Wahrnehmungsprobleme als Folgen der neuen Verklärungswirklichkeit; Nicht-Erkennen als Schuld der Jünger - finden sich in verschiedenen Variationen bei denjenigen Autoren, die an der Schwelle zur Hochscholastik stehen. ${ }^{39}$

\subsection{Zwischen göttlicher Pädagogik und natürlicher Erkenntnispsychologie (Hochscholastik)}

\subsubsection{Die Vollmacht des Verherrlichten (Wilhelm von Auxerre)}

Wilhelm von Auxerre ( $\dagger$ vermutlich 1231), eine der einflussreichsten Vermittlergestalten zwischen Früh- und Hochscholastik, kommt im dritten Buch seiner, Summa aurea' kurz auf die scheinbar falsche Wegankündigung Christi zu sprechen, die er als pädagogischen Anreiz für die Jünger versteht, ihren Herrn um Belehrung und Unterweisung zu bitten. ${ }^{40}$ Noch mehr aber beweist Wilhelm im vierten Buch der ,Summa“ seine wissenschaftliche Überlegenheit gegenüber den meisten Frühscholastikern, indem er für das umfassendere Problem eine Lösung präsentiert, welche die bisherigen Versuche an Kohärenz übertrifft. ${ }^{41}$ Seine Grundthese findet sich auch an anderer Stelle der Auferstehungstheologie: Der österliche Christus besaß nur eine einzige wahre forma, nämlich die verklärte, die er aber in variabler Form zur Erscheinung bringen konnte. Dies tat Christus auch gegenüber den Emmausjüngern: Wie ein Chamäleon vermag der als solcher unveränderte Leib unterschiedliche Wirkungen im Gesichtssinn der Jünger hervorzurufen. $\mathrm{Ob}$ dies auf übernatürliche oder natürliche Weise ge-

Zur generellen Abhängigkeit Gregors von Augustinus in der Lügenthematik vgl. Ramsey [Anm. 5], S. 514f.

37 So etwa bei Radulfus Ardens, ,Homiliae de tempore‘ 53 (PL 155, Sp. 1858C): Sed quod intus habebant, hoc eis exterius exhibuit. Et quia de se dubitabant, se dubium esse demonstravit eis.

38 Langton, f. 325rb, schwankt zwischen diesen Ansichten (Ebbesen/Mortensen [Anm. 33], S. 175): Solutio: Dicimus quod discipuli, quando viderunt eum, [viderunt eum] in forma glorificata et vere tetigerunt; sed cum evangelium non determinet, quod duobus discipulis apparuerit in forma glorificata sed in forma peregrini, potest dici quod tunc viderunt quandam formam obscuram, quae non erat in eo sed in aere circumfuso, et ea mediante visu corporis eum videbant et discernebant sicut in tranfiguratione mediante clara forma quae erat in aere circumfuso videbant eum, quia visus eorum illam formam penetrabant et corpus ipsius vere tangebant. Später in derselben Handschrift, f. 325va (Ebbesen/Mortensen [Anm. 33], S. 176): Nota, quod dici posset duobus discipulis apparuit glorificatus et in forma propria glorificata, nec fuit in aliqua forma assumpta in aere, sed eis videbatur (quia aurisia erant percussi) quod esset forma peregrini; et tamen dicerem quod in transfiguratione fuit secus, quia ibi fuit quaedam forma in aere circumfuso. Davon abhängig: Cod. lat. mon. 9546, $f$. 183rb (Heinzmann [Anm. 26], S. 200); Gaufried von Poitiers, ,Summa', Cod. Paris Nat. lat. 3143, f. 113va (Heinzmann [Anm. 26], S. 231f.).

39 Vgl. etwa Philippi Cancellarii Parisiensis ,Summa de bono', II. Hrsg. v. Nikolaus Wicki (Corpus philosophorum medii aevi. Opera philosophica mediae aetatis selecta 2). Bern 1985, ,De iustitia', quaestio [im Folgenden nur q.] 8, S. 1023-1024.

40 Wilhelm von Auxerre, ,Summa aurea', 3,45,4, q. 3 (Ribaillier [Anm. 32], S. 871): Et est simulatio doctrine, sicut Dominus fixit se longius ire, ut invitaretur a discipulis ad doctrinam et eruditionem. Vgl. ebd. auch schon c. 2, sed contra (zur Frage, ob die Lüge eine Todsünde ist). Ribaillier verweist als mögliche Quelle auf Praepositinus, ,Summa', 1. 2, Cod. Paris Nat. lat. 14526, f. 28va.

4) Vgl. zum Folgenden Wilhelm von Auxerre, ,Summa aurea', 4,18,2, q. 3, solutio (Ribaillier [Anm. 32], S. 488f.). 
schehen konnte (per miraculum sive per potentiam), lässt Wilhelm offen. Damit aber kann Christus zugleich "strahlend“ (clarus) sein und „dunkel“ (obscurus) erscheinen, ohne dass ein Gegensatz zu beklagen wäre. Während so die naturphilosophische Seite des Problems entschärft ist, muss in moralischer Hinsicht auch Wilhelm die schuldhafte (nämlich durch Zweifel und Unglauben bedingte) „Blindheit" der Jünger betonen, um den Vorwurf absichtlicher Täuschung von Christus fernzuhalten. Er lehrt deshalb: Der verherrlichte Leib vermag prinzipiell in den Augen anderer verschiedene Gestalt anzunehmen, dass er es aber auf dem Weg nach Emmaus tatsächlich tat, haben die Jünger selbst verschuldet. ${ }^{42}$

Wilhelms Position wird exakt übernommen vom Summisten des Cod. Basel B.IX.18, ${ }^{43}$ während der sonst meist treue Gefolgsmann Hugo von St. Cher OP $(\dagger 1263)$ diesmal mehr als Wilhelm jede nachösterliche Veränderung vom Auferstandenen fernzuhalten bemüht ist. ${ }^{44}$ Auch der Oxforder Dominikaner Richard Fishacre $(\dagger 1248)$ bedient sich der Idee einer „Erscheinungsautonomie“ des Verherrlichten, kombiniert diese aber mit der älteren, in Paris kaum mehr herangezogenen Vorstellung von einer den wahren Leib umhüllenden und in seinem Leuchten abgeschwächten „Luftfigur“, die er sich nach Art des Hofes (halo) um Sonne und Mond vorstellt. ${ }^{45}$

Ein Anonymus im berühmten duacensischen Sammelkodex 434, dessen Quästion ,De apparitione Christi' höchstens zwei Jahrzehnte nach der ,Summa aurea' verfasst wurde, steht, was den Lösungsgedanken unseres Problems betrifft, offensichtlich Wilhelm sehr nahe, ${ }^{46}$ wobei in formaler Hinsicht deutlich wird, wie weit die Tendenz zur Verwissenschaftlichung unter aristotelischem Einfluss in der kurzen Zwischenzeit Raum gegriffen hat. Allerdings werden auch zwei sachliche Präzisierungen erkennbar: Zum einen ist klargestellt, dass die Andersartigkeit des Erscheinens Resultat eines (natürlichen) Vermögens des Auferstandenen, nicht aber eines Wunders ist. Zum anderen wird nun im Blick auf die Erkennenden nicht mehr eine moralische Schwäche für das Nichtbegreifen der wahren Gestalt verantwortlich gemacht, sondern eine natürliche Schwäche: Der Umfang einer Erkenntnis, so wird Boethius zitiert, ${ }^{47}$ bemisst sich nach dem Vermögen des Erkennenden, nicht nach dem Vermögen (d. h. dem prinzipiell erkennbaren Gehalt) des Erkenntnisobjekts. So vermochten die Emmausjünger Christus nur in der gewohnten, also leidensfähigen Gestalt wahrzunehmen, obgleich seine eigentliche Gestalt die verherrlichte war. Diese Erklärungsidee wird bei den folgenden Autoren aufgenommen werden.

Ebd., S. 489: Loquentibus de se presenciam suam exhibuit; sed dubitantibus de se speciem sue cognitionis abscondit. Posset tamen ab eis cognosci nisi oculi eorum tenebrentur per aurisiam.

43 F. 142va (Marschler [Anm. 18], II, S. 33).

44 Vgl. Hugo von St. Cher, ,Super Marcum 16 (Opera, Lyon 1668, Bd. 6, f. 125ra): Solutio. Quidam dicunt, quod Dominus quandam formam hominis non glorificati assumpsit in corpore suo. Alii dicunt quod in aere fecit illam. Mihi videtur sine praeiudicio tamen quod nullam formam aliam a suo assumpsit nec in corpore nec in aere, sed habitum peregrini habuit, propter quam videbatur alius nec cognoscebatur, quia percussi erant aurisia, sicut dicit Lucas. [...] Vel forte aer condensatus erat, ut non videretur in sua claritate. Christus kann sich nach der Auferstehung nicht mehr im eigentlichen Sinne ,verändern“, quia alteratio quaedam mors. Richard Fishacre, , In quartum librum sententiarum', Cod. Oxford, Balliol College 57, dist. 44, f. 341 vb-342ra. Vgl. zum Folgenden Anonymus, Quaestio 5: ,De apparitione Christi post resurrectionem et ante ascensionem", Cod. Douai 434, f. 202vb-203va; Textedition: Walter H. Principe, Questions concerning Christ from the first half of the thirteenth century. VI. Quaestiones from Douai MS. 434. Saving activities of Christ. Mediaeval Studies 54 (1992), S. 1-48, hier S. 34-38.

47 Ebd., S. 36, n. 11: Omne quod scitur vel cognoscitur non secundum facultatem sui, sed secundum cognoscentis apprehendit (= Boethius, ,Consolatio philosophiae‘ 5 pr. 4,25, CCL 94, S. 96f.). 


\subsubsection{Bedingtheiten endlicher Objekterkenntnis (,Summa Halensis')}

Auch die Position der Summe des Alexander von Hales, im dritten Buch durch seine Schule, namentlich durch Johannes a Rupella, komplettiert, nimmt ihren Ausgang eindeutig von der Vorgabe Wilhelms. Obwohl dessen Ausführungen mit ausdrücklicher Namensnennung breit zitiert werden, meldet die ,Summa' gewisse Vorbehalte an. ${ }^{48}$ Vor allem die Behauptung, dass die Veränderung der Erscheinungsform auf den Auferstandenen selbst zurückgehe, scheint ihr noch nicht hinreichend geklärt. Dazu wird nun das Axiom von der subjektiven Einschränkung kognitiver Gegenstandspräsenz, das wir schon in der Quästion aus Cod. Douai 434 kennen lernten, noch weiter ins Zentrum der Argumentation gerückt: Was wahrgenommen wird, ist im Wahrnehmenden nur nach dessen eigener Weise (receptum non est in recipiente nisi secundum modum recipientis). Nicht nur im Falle der ungläubigen Jünger, sondern generell bedingt die subjektive Aufnahmefähigkeit des Wahrnehmenden den Umfang und die Qualität seiner Objekterfassung. Damit können Verschiebungen in der Wahrnehmung ein- und desselben Gegenstandes durch mehrere Zeugen rein ex parte recipientis erklärt werden. Entscheidend ist das Vorliegen einer Verhältnismäßigkeit zwischen Wahrnehmungsobjekt und Wahrnehmungsvermögen (proportio visi ad visum): Nur wo sie gegeben ist, findet eine unverzerrte Aufnahme statt. Weil aber ab einem gewissen Grad der Überlegenheit des Objekts gegenüber dem abbildenden Vermögen dieses gänzlich versagt oder sogar zerstört wird, können bestimmte Gegenstände von uns nur erfasst werden, wenn sie zuvor durch vermittelte Kundgabe unseren Sinnen angepasst worden sind. Im natürlichen Bereich gilt dies etwa für unser Sehen der Sonne: Da wir sie nicht unmittelbar anschauen können, ohne zu erblinden, sind wir auf die vorherige Brechung ihrer Strahlen, z. B. durch Wolken, angewiesen. Damit aber ist automatisch eine gewisse Verfälschung verbunden, so dass wir das Sonnenlicht nicht mehr in originaler Intensität, dafür aber in Farben wahrnehmen, welche die Sonne selbst nicht besitzt. Eine solche Anpassung an die Erkenntniskraft der Betrachter ist nach der ,Summa Halensis“ nun auch angesichts des Glorienleibes Christi vonnöten: Die Jünger sehen denselben Leib, aber ,wegen unserer (menschlichen) Schwachheit" nicht als denselben. Sie sehen ihn zudem überhaupt nur, weil er sich ,angepasst" (secundum naturam quam capere possunt) zeigt, nämlich so, dass aus dem Lichtleib, der die natürliche menschliche Sehkraft vernichten müsste, ein solcher wird, der zu unserem Sinnesvermögen in Proportion steht.

Der Vorteil der hier entwickelten Lösung besteht darin, dass Christus in keiner Weise mehr als Verursacher täuschender Sinneswahrnehmungen in Frage kommt. Er verändert keinesfalls die Sinne der Rezipienten, höchstens sein eigenes Erscheinungsbild, insofern er es überhaupt erst den bescheidenen menschlichen Vermögen zugänglich macht. Diese subjektiven Wahrnehmungsbedingungen aber werden kriteriologisch viel umfassender in den Blick genommen als bei Wilhelm von Auxerre: Im Sinne einer generellen natürlichen Schwäche erklären sie die unterschiedlichen Erscheinungen des Auferstandenen auch vor solchen Zeugen, denen keine schuldhaften Dispositionsmängel nachzuweisen sind. Genauso gut aber, und damit wird anders als in Cod. Douai 434 ebenfalls die ältere These integriert, kann ein schuldhaft bedingtes „Vorurteil“ zum (zusätzlichen) Wahrnehmungshindernis erklärt werden, so dass der Summist für den Fall der Emmausjünger, wie zuvor Wilhelm, den 
inneren Zweifel als Ursache der äußeren Fehleinschätzung ansetzen kann. ${ }^{49}$ Dafür, dass die Jünger sie schließlich im Augenblick der Brotbrechung doch noch überwunden haben, kennt der Summist unterschiedliche Erklärungsversuche. ${ }^{50}$

Die Grundthese der ,Summa Halensis` teilt die zweite Auferstehungsquästion des Cod. Todi 71, die HENQUINET dem Dominikanermagister Guerricus von St. Quentin ( $†$ um 1245) zugeschrieben hat: ${ }^{51}$ Christus erscheint in seiner eigenen (d. h. verherrlichten) Gestalt, doch im Modus des Sich-Hinabbegebens (condescensio) auf die Ebene menschlicher Aufnahmefähigkeit, was notwendig eine Abmilderung (contemperantia) des Herrlichkeitsglanzes und damit möglicherweise für die Betrachter (ex parte videntium) Veränderungen in der Gestaltwahrnehmung mit sich bringt. ${ }^{52}$ Ähnliche Gedanken äußert neben dem schon erwähnten Text Richard Fishacres eine anonyme Auferstehungsquästion aus einer Prager Handschrift, ${ }^{53}$ die vermutlich $1240-1250$ im Dominikanermilieu entstanden ist. ${ }^{54}$

\subsubsection{Offenbarung der souveränen Weisheit Gottes (Wilhelm von Baglione)}

Die zwei Stellen im Sentenzenkommentar Bonaventuras $(\dagger 1277)$, die sich bei der Erörterung der Lüge bzw. im Zusammenhang mit der Eucharistie der Emmausperikope widmen, ${ }^{55}$ wirken gegenüber den zuvor besprochenen Texten eher traditionell, sofern sie zwar die wichtigsten Motive der Diskussion nennen (Verstockung der Jünger als Strafe ${ }^{56}$ - pädagogische simulatio doctrinae vs. böse simulatio duplicitatis) ${ }^{57}$, nicht aber auf das (generell) eingeschränkte menschliche Erkenntnisvermögen rekurrieren. Dies mag allerdings auch mit

Ebd. mit einer interessanten Alltagsanalogie: Hoc etiam possumus nos videre frequenter quod dubitatio interior animae facit etiam exteriorem dubitationem. Unde, cum dicitur de hoc homine quod alibi sit, si aliquo casu videretur, hic ratione interius dubitationis crederetur non esse; sic cum dicitur: ,Tu solus peregrinus ', intelligitur peregrinus, id est extraneus, secundum quod eis videbatur propter dubitationem interiorem.

Ebd. ad obiecta (Schluss). So könnte das Wiederkennen gelungen sein propter quendam specialem modum frangendi ex virtute manus Christi, quia sua fractio erat velut cultelli incisio. Ähnlich Albertus Magnus, ,De resurrectione'. In: Opera omnia. Bd. 26. Hrsg. v. Albert Ohlmeyer, Ignaz Backes u. Wilhelm Kübel. Münster 1958, tract. 2, q. 8, art. 6, § 4 ad 4 (S. 281, Z. 19-21).

51 François-Marie Henquinet, Notes additionelles sur les écrits de Guerric de Saint-Quentin. Recherches de Théologie Ancienne et Médiévale 8 (1936), S. 369-388.

52 ,Quaestio de resurrectione', solutiones zu Art. 1-3, ediert bei Marschler [Anm. 18], II, S. 100f.

53 Anonymus, Cod. Prag Univ. IV.D.13, ,Quaestio de resurrectione', a. 5-8, ediert bei Marschler [Anm. 18], II, S. 131-136. Auch hier erfolgt eine Auseinandersetzung mit dem Axiom Omne quod cognoscitur, cognoscitur secundum capacitatem cognoscentis (art. 7, ad 2 [Marschler [Anm. 18], II, S. 135]). Allerdings fällt wie auch sonst auf, dass die Verbindung zur ,Summa Halensis‘ bestenfalls indirekt sein kann; wörtliche Berührungen fehlen. Was den Erscheinungsmodus vor den Emmausjüngern angeht, wird noch die alte These von der forma assumpta ex aëre vertreten.

54 Bernard-G. Guyot, Quaestiones Guerrici, Alexandri et aliorum magistrorum Parisiensium. Archivum Fratrum Praedicatorum 32 (1962), S. 5-123, bes. 113.

55 Bonaventura, ,Commentarius in tertium librum sententiarum [Magistri Petri Lombardi]' (Opera omnia. Hrsg. v. Collegium S. Bonaventurae. Quaracchi 1889), dist. 38, art. 1, q. 2 ad 3; ,Commentarius in quartum librum sententiarum", dist. 12, pars 1, dubium 1.

56 Bonaventura, 4 Sent. dist. 12, p. 1, dub. 1 : Sensus enim exterior formam videbat veram, interior non decipiebatur, sed claudebatur.

57 Bonaventura, 3 Sent. dist. 38, art. 1, q. 2 ad 3: Simulatio vero doctrinae fuit in Christo, cum finxit se longius ire, sicut dicitur Lucae ultimo, 28; in quo erudivit discipulos officium hospitalitatis, quo coegerunt illum apud

- se manere, per quod meruerunt etiam illum cognoscere. Das Lernziel für die Jünger wird also ein wenig anders verstanden als bei den vorangehenden Autoren. Vgl. auch Bonaventura, ,Commentarius in evangelium S. Lucae', cap. 9, 29, 51 (Opera omnia. Bd. 7. Quaracchi 1895, S. 233), wo von einem „dispensativen" SichVerbergen die Rede ist. 
den genannten Kontexten der Erörterung zu tun haben, die jeweils nur an einem bestimmten Aspekt der Thematik, nicht an einer umfassenderen Auslegung dieses Erscheinungsberichts interessiert sind.

Weitaus klarer und eingehender als Bonaventura hat sich einer seiner franziskanischen Zeitgenossen, der Magister Wilhelm von Baglione, mit unserem Problem auseinandergesetzt. Er behandelt es in einem etwas größeren Kontext, wobei aber die Doppelperspektive seiner Frageformulierung (aus der Sicht Christi und der Auferstehungszeugen) durchaus im Rahmen der uns bekannten Erörterungen verbleibt: Brachte die Vielzahl der Erscheinungen Veränderung im Sinne von Zerstörung für den Erscheinenden und Veränderung im Sinne von Täuschung bei den Betrachtenden mit sich ${ }^{58}$

Wilhelm geht so vor, dass er zunächst den ersten Aspekt in den Blick nimmt, um mit dem dadurch gewonnenen Instrumentarium auch den zweiten mitbeantworten zu können. Am Anfang steht ein mögliches zweifaches Verständnis von Veränderung (mutatio): Sie kann zum einen begriffen werden als Auflösung der Identität eines Dinges - sie berührt dann dessen ontologische Eigentümlichkeit (proprietas essendi). Ebenso aber kann mit dem Wort die Unterbrechung der Gleichförmigkeit (uniformitas) eines Gegenstandes angezielt werden; diese Art von Veränderung beträfe nur den Existenzmodus (modus existendi sive se habendi) des Gegenstands, nicht aber sein Wesen. Die erste Weise, die Wilhelm auch als Veränderung im eigentlichen Sinne (proprie accepta) klassifiziert, ${ }^{59}$ ist notwendig mit Zerstörung (nämlich der Wesensform) verbunden und kann deshalb für den verklärten Christus generell ausgeschlossen werden. Veränderung im zweiten Sinne kann ebenfalls nicht ohne Weiteres prädiziert werden, zuvor muss man sich die möglichen Gründe bewusst machen, aus denen sie hervorgeht.

Nach Wilhelm sind bei einem Subjekt (konkret ist nur an Menschen gedacht) drei solcher Gründe möglich, die eine Veränderung des Existenzmodus im Gefolge haben: Erstens kann eine „tadelnswerte Schwäche“ (etwa im Sinne charakterlichen Wankelmutes) zugrunde liegen. Zweitens bringt die unüberwindliche Unvollkommenheit des endlichen Seienden Veränderlichkeit mit sich - jede Kreatur ist immer nur Teil, niemals das Ganze der Welt, was sich etwa in der notwendigen örtlichen Begrenztheit des Aufenthalts bzw. Wirkens niederschlägt, die ohne „Diskursivität“ im wörtlichen Sinne nicht auskommen kann. Drittens aber ist auch eine positive Ursache für Veränderlichkeit denkbar. Es gibt die Vollmacht dessen, der anderen vorgesetzt ist und der dadurch die Freiheit hat, wechselnde Anordnungen und Verfügungen zu treffen. Es leuchtet ein, dass in der Übertragung auf Christus diese dritte Ursächlichkeit entscheidend ist. Weil Christi Seele nach der Auferstehung volle Verfügung (praesidentia) über seinen Leib besitzt, wird die mögliche Vielgestaltigkeit zu seiner Eigenschaft, ganz so, wie die Seele es will. Diese These wird im Mittelalter seit Wilhelm von Auxerre dem frühscholastischen Magister Praepositinus von Cremona zugeschrieben, ohne dass sie in dessen Texten bisher nachgewiesen werden konnte. ${ }^{60}$ Gegenüber den Jüngern wird diese Vollmacht nach Wilhelm von Baglione nicht willkürlich eingesetzt, sondern

Wilhelm von Baglione, Cod. Florenz, Bibl. Naz. Conv. Soppr. B 6.912, f. 40vb-45va: Utrum varietas apparitionum [...] ponat aliquam mutationem in apparente, quae debebat dici corruptio, et aliquam in aspicientibus, quae debebat dici illusio, ediert bei Marschler [Anm. 18], II, S. 159-161. Soweit nicht anders vermerkt, bezieht sich das folgende Referat auf das Corpus articuli.

60 Marschler [Anm. 18], I, S. 391 mit Anm. 157. 
sie kommt wiederum gemäß einer dreifachen göttlichen Maxime zur Ausführung: Erstens secundum sapientiam coaptantem, zweitens secundum iustitiam occultantem und drittens secundum pietatem condescendentem. Man erkennt unschwer, dass der erste Begriff durch den zweiten und dritten erläutert wird: Die Erscheinungen Christi passen sich ,nach Maßgabe der göttlichen Weisheit“ ihren Adressaten an. Dies wird darin konkret, dass sich der Auferstandene zeigt und verbirgt, wie es der ,Zustand der Empfänger“ - und speziell ihr sittlicher Zustand - verlangt (secundum statum recipientium et secundum quod in corde habuerunt). So ist es ,gerecht“, wenn er sich vor Zweifelnden verbirgt bzw. ihnen nur verborgen erscheint. Zugleich bezeugt es die Güte des Herrn, wenn dieser sich stets so zu den Menschen „herabbegibt", dass sie ihn in der Schwäche ihres Wahrnehmungsvermögens überhaupt erfassen können. Damit ist das ganze Spektrum von Erklärungen, wie sie die bisherige Debatte beherrschten, geschickt zusammengefasst. Wilhelm kann festhalten: Christus veränderte sich in der Kundgabe der Auferstehung, allerdings nicht in sich, in esse absoluto, sondern nur im Verhältnis zu anderen, in esse relato, nämlich sofern er durch andere wahrgenommen wurde. ${ }^{61}$

2.2.4 Wahrhaftige Erscheinung und eingeschränkte Wahrnehmung (Albertus Magnus) Bei Albert dem Großen $(\dagger 1280)$ steht die Frage nach dem Sich-Zeigen des Auferstandenen vor allem unter der Prämisse einer generellen natürlichen Unzugänglichkeit des verherrlichten Leibes für die Sinne der Nicht-Verklärten. Es gehört nicht zu den aus der Glorie selbst resultierenden Eigenschaften, sich nach Belieben in der unverklärten Welt zeigen zu können - dies geschieht allein aus der Kraft und Anordnung Gottes, der in seiner Weisheit die ihm untergeordneten Dinge ,zum Nutzen der Gläubigen“ zu bewegen versteht. ${ }^{62}$

Den Modus des Sichtbarwerdens denkt sich Albert in ,De resurrectione“ auf folgende Weise $:^{63}$ Ein Wunder Gottes ist nötig, damit der verklärte Leib ein nicht-verklärtes Auge so verändern kann, dass er darin sichtbar wird. Ist diese an sich unüberwindliche Kluft durch Gottes Hilfe geschlossen, ergibt sich eine zweifache Möglichkeit: Entweder verläuft nun der eigentliche Sehvorgang, der wie gewöhnlich als Aufnahme der den Gesichtssinn verändernden sinnlichen Dingform zu definieren ist, gemäß der (natürlichen) Fähigkeit des unverklärten Auges auf natürliche Weise, nämlich mit Hilfe von Farbeindrücken - dann wird sub forma coloris ein leiblich-begrenzter Körper gesehen. Damit verweist auch Albert auf die subjektive Bedingtheit der Wahrnehmung, welche die Jünger vom Auferstandenen haben. Um diese zu überwinden, würde ein zweites Wunder nötig, das nicht nur von Seiten des handelnden Christus her (ex parte immutantis), sondern auch auf Seiten der Betrachter (ex parte videntis) eine Veränderung herbeiführt, die das natürliche Sehvermögen (die potentia visiva) übersteigt und mit deren Hilfe der verherrlichte Leib in seiner Verherrlichungsgestalt, sub lumine, wenn auch unter den bleibenden Bedingungen verklärter Leiblichkeit (Al-

Dieselbe Unterscheidung wird auch schon in der Antwort auf einen Einwand des vorangegangenen Artikels expliziert: q. 2, ad 11-12, ediert bei Marschler [Anm. 18], II, S. 156f.

62 Albertus Magnus, ,De resurrectione', tract. 2, q. 8, art 3. solutio ([Anm. 50], S. 276, Z. 47-49): Dicimus quod corpus gloriosum sine miraculo non est visibile a non-glorioso; ebd. ad 7 (Z. 77-82): in potestate corporis gloriosi non est videri et non videri quando vult. Sed quod quandoque videtur et quandoque non, hoc est ex potestate sapientiae divinae, quae movet res inferiores non tantum per naturam, sed etiam per miraculum ad utilitatem credentium.

63 Vgl. zum Folgenden ebd. solutio. 
bert spricht von einer terminatio corporis), ${ }^{64}$ begriffen werden kann. Der erste Fall liegt bei jenen Erscheinungen vor, in denen der Auferstandene mit Eigenschaften seiner irdischen Leiblichkeit wahrgenommen wird; im zweiten Fall müsste er wohl so erscheinen wie in der Verklärung.

An dieser Stelle kann Albert in eine Diskussion mit früheren Positionen eintreten. Wie bei den anderen Hochscholastikern findet die frühscholastische These (ausdrücklich charakterisiert als opinio antiquorum), nach der Christus sich bewusst in fremder Gestalt zeigte, keine Zustimmung mehr. ${ }^{65}$ Eine Differenz von (wahrer) forma und (absichtlich je verschieden immutierter) species gibt es nicht, es sei denn, die scheinbar verschiedene Gestalt meine die forma suscepta, ${ }^{66}$ also das Ergebnis der Wahrnehmung im erkennenden Subjekt. Alle Verschiedenheit der Wahrnehmung gründet im unterschiedlichen Wahrnehmungsmodus der Betrachter. Wie die ,Summa Halensis' beseitigt damit auch Albert nachdrücklich das Schwanken, wie es bei Wilhelm von Auxerre noch zu beobachten war, in Richtung einer einheitlichen erkenntnispsychologischen Erklärung. Allerdings muss sich das naturphilosophische Beispiel der ,Summa' (von dem im Medium farblich gebrochenen Sonnenlicht) einige Korrekturen durch den mit Aristoteles weit besser vertrauten Albert gefallen lassen. ${ }^{67}$

In einem eigenen Paragraphen wendet Albert sein prinzipielles Modell auf das Beispiel der Emmausjünger an. Da sich Christus auf jeden Fall in seiner eigentümlichen Gestalt zeigte und nur so die Herzen der Weggenossen zum „Brennen“ bringen konnte, ${ }^{68}$ muss der Irrtum der Jünger in der Identifizierung durch eine weitere Bedingung erklärt werden. Damit jeder Verdacht einer lügenhaften fictio ausgeschlossen wird, ${ }^{69}$ hat man neben der natürlichen Beschränktheit der Wahrnehmungsfähigkeit auch noch die besondere Beschaffenheit der Situation zu berücksichtigen. Wie kaum anders zu erwarten, greift Albert dabei auf das bekannte Motiv der durch Zweifel behinderten Vernunft zurück, ${ }^{70}$ welche die Zuordnung der Gestalt zum richtigen Träger verunmöglicht. Anders als die bisherigen Autoren will Albert aber auch diese zweite Bedingtheit noch einmal exakter erkenntnispsychologisch verständlich machen, wie vor allem im Lukaskommentar zu sehen ist: Wenn Menschen auf Grund inneren Zweifels einem äußeren Eindruck nicht trauen und ihn für unmöglich halten, beeinflusst dies ihr Sehen. ${ }^{71}$ Noch grundsätzlicher gilt: Eine vorgängige innere Einschätzung ist verantwortlich da-

Ebd. ad 11.12 (S. 277, Z. 17-22): Perceptio enim illa causatur a duobus, scilicet a defectu potestatis oculi nongloriosi et a terminatione corporis quod videtur. Cuius terminatio est in compositione et commixtione elementali secundum substantiam, quamvis non sint in eo actu qualitates activae et passivae.

66 Ebd. ad 9.

${ }^{67}$ Ebd. ad 10 (S. 276f.). Die Detailfrage nach der Farblichkeit des Leibes ist für uns unerheblich.

68 Ebd., tract. 2, q. 8, art. 6, $\S 4$ ad 6 (S. 281).

69 Sogar die Bemerkung des Evangelisten, Jesus habe getan (finxit), als wolle er weitergehen, wird zum Problem gemacht; die Antwort darauf ebd. ad 3 und auch ,Super Lucam`24, 29 (Opera omnia, hrsg. v. Auguste Borgnet. Paris 1890 , hier Bd. 23, S. 760a), wo zumindest eine „erlaubte Form“ von fictio anerkannt zu werden scheint: Attende autem quod licet fictio nullo modo conveniat veritati, hanc veritatem haec fictio habuit, quae hoc praetendit quod in mente eorum iam fuit. Longius enim aberat a mentibus eorum. Die äußere Täuschung dient also zum Nachweis einer inneren Wahrheit und ist durch diesen „enthüllenden“ Charakter gerechtfertigt.

70 Vgl. ebd. ad 1: ratio impedita dubitatione.

71 Oculi autem illorum, scilicet discipulorum, tenebantur, non quidem a Domino, sed interiori dubitatione: sicut quando homo non confidit de aliquo quod appareat, et iudicat impossibile quod ille [illud?] sit, statim interior aestimatio speciem visam ante oculos convertit ad aliud: Albertus Magnus, ,Super Lucam‘ 24,16 ([Anm. 69], Bd. 23, S. 753b). Ausdrücklich lehnt Albert die Meinung ab, diese Fehlsichtigkeit sei mit der biblischen aurisia (von Borgnet falsch: acrisia) identisch, auf die sich viele Interpreten vor ihm berufen hatten. 
für, dass wir Sinneseindrücke in einer bestimmten Weise kombinieren und deuten, die keineswegs der Realität entsprechen muss. Wer z. B. Angst hat, ,sieht" auf einmal wilde Tiere, doch diese verdanken ihre Existenz tatsächlich nur der subjektiven Imagination, die diverse Wahrnehmungsbilder falsch ergänzt und so zu sehen meint, was sie von Anfang an erwartet hat. Ähnliche Täuschungen sind auch bei positiven Vorerwartungen möglich. ${ }^{72}$ Auf jeden Fall wird dadurch erklärlich, weshalb die durch Zweifel und Furcht vor den Juden beeinflussten Jünger die Erscheinung des Auferstandenen nicht richtig zu deuten wussten.

Auf die Texte in Alberts Sentenzenkommentar braucht nicht mehr ausführlich eingegangen zu werden, da sie die beiden Charakteristika unterstreichen, die wir mit Blick auf ,De resurrectione" herauszustellen versucht haben. Indem Albert in einem eigenen Artikel des Traktats über das Altarssakrament die österliche Erscheinung Christi „in fremder Gestalt“ zur Problematik einer eucharistischen Wesensverwandlung unter Fortbestehen der „falschen" Gestalten in Beziehung setzt, ${ }^{73}$ wird klar, dass er dem Trend des 13. Jahrhunderts zu einer immer „wörtlicheren“ Auslegung des Handelns Gottes folgt, die dessen symbolischsakramentale Deutung nur dann zulässt, wenn es zuvor auch im Litteralsinn der Beschreibungsebene als wahrhaftig erwiesen wurde. Die Erscheinung des Auferstandenen, so könnte man Alberts Worte interpretieren, ist wie die Eucharistie res et sacramentum und in beider Hinsicht unverkürzt wahr: Sofern sie Ausdruck von etwas Verborgenem ist, deckt sie den Glaubenszustand der Jünger auf $\mathrm{f}^{74}$ und ist damit Träger einer positiven Intention Christi, fast ähnlich einer prophetischen Zeichenhandlung; ${ }^{75}$ sofern sie als eigenständiges Geschehen betrachtet werden kann, wird dessen verzerrte Rezeption durch die schon bekannte doppelte Bedingtheit des Wahrnehmungsvermögens der Jünger (natürliche Disproportionalität schuldhafter Zweifel) erklärbar. Damit ist auch der zweite Schwerpunkt integriert, der bereits die Ausführungen von ,De resurrectione‘ ausgezeichnet hatte.

\subsubsection{Kein „Sehen“ ohne „Glauben“ (Thomas von Aquin)}

Thomas von Aquin zeigt ein eher geringes spekulatives Interesse an unserer Fragestellung; wahrscheinlich hat er erkannt, dass nach der ausführlichen Diskussion der vorangehenden Zeit kaum mehr neue Aspekte einzubringen sind. Mit den meisten Zeitgenossen ist sich Thomas bereits im frühen Sentenzenkommentar ${ }^{76}$ einig, dass Christus den Jüngern seine

72 Ebd. (S. 754a): Sed potius [sc. passi sunt discipuli], sicut videmus in timentibus et dubitantibus, quod modicas iuncturas et valde dissimiles propter imaginationem interiorem putant esse animalia nociva et fugiunt: aut forte aliquid desiderabilium, et tunc accedunt.

73 Albertus Magnus, ,Commentarii super quartum librum sententiarum". In: Opera omnia. Hrsg. v. Auguste Borgnet. Bd. 29. Paris 1894, dist. 13, art. 3 (S. 337f.): An quando Christus ostendit se discipulis in via in specie peregrini, fecerit actum simulatorium sive illusorium?

74 Ebd. ad 1 (S. 337): intentum in opere fuit ostendere eis per similitudinem qualis fuit tunc in mentibus discipulorum, et quoad hoc verissime et non similitudinarie egit; quia nullus alius ita hoc demonstrat.

75 Ebd.: sicut etiam nos dicimus simulare Ezechielem, quando fecit perfodi domum, et latenter se exportari. Daneben erwähnt Albert als zweite Intention Christi die Bestärkung des Auferstehungsglaubens der Jünger nach Beseitigung der vorübergehenden „Blindheit“. Weil es sich dabei aber nur um einen „nachfolgenden“ Effekt handelt, kann das Argument nicht zur Bewertung der Erscheinung in sich herangezogen werden: intentum autem per opus non fuit in opere, sed consequens ipsum, scilicet confirmatio fidei discipulorum quoad articulum resurrectionis, et hoc est extra opus, et non facit opus verum, vel simulatorium, sed potius primum [sc. intentum in opere] (ebd. ad 1).

76 Zum Folgenden Thomas Aquinas, , In tertium librum sententiarum [Petri Lombardi]‘. Hrsg. v. Maria F. Moos. Paris 1933, dist. 21, q. 2, art. 4, solutio 1 ad 3 (S. 653f.); , In quartum librum sententiarum'. Hrsg. v. Maria F. Moos. Paris 1947, dist. 12, q. 3, art. 2 (S. 539), expositio textus. 
wahre Gestalt, wenn auch als unverklärte, zeigte - für Thomas, wie aus Darlegungen andernorts deutlich wird, eine grundsätzliche Möglichkeit des Auferstandenen. Weitere naturphilosophische Erklärungsversuche, wie sie Albert entwickelt hatte, unterbleiben. In der Frage, weshalb die korrekt wahrgenommene (d. h. gesehene) Gestalt von den Jüngern falsch gedeutet wurde, geht Thomas größeren wahrnehmungspsychologischen Exkursen aus dem Weg und kehrt zur einfachen moralischen Deutung Augustins und Gregors des Großen zurück: Die Jünger erkannten den Herrn nicht, weil sie nicht an seine Auferstehung glaubten. ${ }^{77}$ Bei der Explikation klingt allerdings Alberts Lehre von der kognitiven Täuschungskraft des Vorurteils an: Wer einen Menschen sicher für tot hält, erkennt ihn auch dann nicht, wenn er ihm (womöglich noch in ungewohnter Gewandung) leibhaft begegnet. ${ }^{78}$ Weil in diesem Sinne die Jünger ihr vorgefasstes Urteil in der Begegnung mit dem scheinbar fremden Weggefährten nicht überprüfen, verbleiben sie in ihrer Täuschung, bis sie durch die in bestimmter Weise vorgenommene Brotbrechung ${ }^{79}$ ein unverkennbares signum speciale erhalten. Freilich lässt Thomas auch diejenige Position gelten, die eine bloße Analogie zu normalen (schuldhaften) Erkenntnisblockierungen in diesem Falle für nicht ausreichend erachtet: Dann muss die „Behinderung“ im Übergang von Sehen und Erkennen wieder als Werk der virtus divina qualifiziert werden, deren Unterscheidung von der Lüge man mit Augustins bekannten Argumenten vornehmen kann. ${ }^{80}$ So ist die schon in der Frühscholastik bestehende Zwiespältigkeit der Erklärungsversuche weiterhin präsent.

Die ,Summa theologiae" widmet unserer Frage immerhin einen eigenen Artikel (III, 55, 4). Augenfällig ist, dass Thomas die Antwort nun im umfassenderen Begriffshorizont seiner Theorie übernatürlicher Offenbarung formuliert, wie sie die ganze Quästion durchwirkt. Es ist nicht mehr bloß von einer Reaktion Gottes auf den konkreten Unglauben der beiden Jünger die Rede, sondern von einer grundsätzlichen Entsprechung zwischen dem Modus der göttlichen Offenbarung und der Disposition zum Glauben bei den Rezipienten. ${ }^{81}$ Allgemeiner könnten wir sagen: Um die Gegenstände des übernatürlichen Glaubens (fides quae) zu erfassen, muss bereits Glaube im Sinne ungetrübter, gnadengewirkter Bereitschaft (die fides $q u a$ ) vorhanden sein. Damit tendiert Thomas hier klarer als im Sentenzenkommentar dazu, nicht ein aktives Wirken, sondern nur eine „Zulassung“ Gottes mit der Blindheit der Jünger $\mathrm{zu}$ verbinden, die diese selbst $\mathrm{zu}$ verschulden haben. ${ }^{82}$ Alle weiteren Erläuterungen, die sachlich nicht vom Sentenzenkommentar abweichen, gibt Thomas in den Einwänden des Artikels fast ausschließlich durch aneinandergereihte Augustinuszitate: Die Lehre der Tradi-

77 Ähnlich auch 4 Sent. d. 12, expositio textus.

783 Sent. dist. 21, q. 2, art. 4, sol. 1 ad 3: Unde [sc. discipuli] non ponebant se ad perquirendum iudicia propria, quibus possent ipsum cognoscere; sicut etiam accideret, si videremus aliquem quem mortuum crederemus, quamvis notus nobis fuisset, et maxime si videremus illum in alio habitu.

79 Die etwas merkwürdig anmutende Erklärung: quia, ut dicitur, sua fractio erat similis incisioni cultelli (ebd.) kennen, wie bereits erwähnt, sowohl die ,Summa Halensis‘ als auch Albertus Magnus.

80 Auf diese Alternative kommt Thomas noch einmal in der Sakramentenlehre zu sprechen, wo er bestimmte eucharistische Wunder zu erklären sucht: Wenn Christus im Sakrament unter bestimmten Gestalten erscheint, ist dies nicht als (böswillige) Täuschung zu verstehen, sicut etiam Christus absque deceptione apparuit discipulis euntibus in Emmaus. Dicit enim Augustinus in libro de Quaestionibus Evangelii [Buch 2, quaestio ultima; $\mathrm{PL}$ $35, \mathrm{Sp} .1362]$, quod, cum fictio nostra refertur ad aliquam significationem, non est mendacium, sed aliqua figura veritatis: ,Summa theologiae‘. In: Thomas de Aquino, Opera omnia. Hrsg. v. Commissio Leonina. Bd. 12. Roma 1906, Teil III, q. 76, art. 8 (S. 191f.).

81 ,Summa theologiae' (Opera omnia. Bd. 11. Roma 1903), Teil III, q. 55, art. 4 (S. 519).

82 Ebd,, art. 4 ad 3 (S. 519). 
tion wird bestätigt, ohne dass noch an einer argumentativen Vertiefung im Sinne früherer Scholastiker Interesse bestünde.

\section{Zusammenschau}

1. Die Behandlung der Emmausperikope in Früh- und Hochscholastik, soweit wir sie verfolgen konnten, ist in ihren Grundlinien eine getreue Rezeption der augustinischen Interpretationsideen zur Abwehr des Vorwurfs, Christus habe seine Jünger getäuscht. Anlass und Kontext der Erörterungen haben sich allerdings verändert. Spürbar ist vor allem bei Autoren des 13. Jahrhunderts der fortschreitende Versuch, die augustinische Schriftauslegung in den umfassenderen Kontext einer systematischen Auferstehungstheologie einzuordnen. Hier wird die Frage, welche Möglichkeiten des Sich-Zeigens und Sich-Verbergens dem verklärten Leib des Herrn zukommen konnten, umfassend und in ständiger Auseinandersetzung mit den einschlägigen biblischen Vorgaben diskutiert. ${ }^{83}$ Die bei Augustinus im Fall der Emmausjünger nicht in Erwägung gezogene Möglichkeit, dass die von den Jüngern gesehene, aber zuerst nicht identifizierte Gestalt auf eine Veränderung des Aussehens Christi selbst zurückgeht, wird zunehmend akzeptiert, da die Annahme, Christus selbst habe ein „Hindernis“ in den Wahrnehmungssinnen der Jünger zugelassen oder herbeigeführt, den Scholastikern offensichtlich problematischer erscheint als Augustinus.

2. Indem sich die Scholastik weniger schnell mit der Berufung auf ein mysterium im Sinne einer Kundgabe geistlicher Wirklichkeit durch Gott im für sich allein, dem Litteralsinn nach nicht hinreichend verständlichen Offenbarungsgeschehen zufrieden gibt, verschärft sich das Wahrhaftigkeitsproblem für die Schriftauslegung. Im Verbund mit der seit der Viktorinertheologie des 12. Jahrhunderts zu beobachtenden Tendenz, den Litteralsinn der Schrift vor allen geistlich-allegorischen Schriftsinnen ernst zu nehmen und zu erheben, lässt sich das Bemühen vieler Scholastiker begreiflich machen, in der Emmausperikope nicht bloß wie Augustinus und andere Väter eine heilspädagogisch gerechtfertigte Intention aufzuweisen, die das Verhalten des Herrn in Lk 24 vom Vorwurf der unerlaubten Täuschung befreit, sondern darüber hinaus zunehmend metaphysische, naturphilosophische und erkenntnispsychologische Spekulationen darüber anzuschließen, wie ein „wahres Sehen ohne wahres Erkennen" möglich gewesen sein mag.

3. Diese Beobachtungen erklären sich des weiteren aus Veränderungen der Koordinaten im theologischen Themenfeld ,Glaube und Offenbarung;, wie sie sich auf der Wende ins 13. Jahrhundert spürbar vollziehen. Wenn sich die mittelalterliche Theologie im Zeitalter ihrer fortschreitenden Verwissenschaftlichung mit der ethischen Qualifizierung der Lüge auch Augustins Musterlösungen für biblische Zweifelsfälle zu eigen macht, rückt die offenbarungstheologische - man könnte in moderner Terminologie auch sagen: fundamentaltheologische - Dimension des Wahrhaftigkeitserweises gegenüber der rein ethischen vor allem dort in den Vordergrund, wo es um Worte und Taten Christi selbst geht. Zwar ist die Frühund Hochscholastik noch nicht jenem ,extrinsezistischen“ Verständnis von Offenbarung verpflichtet, in welcher die Person Christi in ihrem Reden und Handeln für die Glaubwürdigkeit eines lehrhaft konzipierten Offenbarungsinhalts einsteht, der als solcher von ihr trennbar zu sein scheint. Dennoch gewinnt mit der vor allem durch die Aristotelesrezeption 
des 13. Jahrhunderts unausweichlichen wissenschaftstheoretischen Ortbestimmung der Theologie ${ }^{84}$ und ihrer Abgrenzung von allen Formen natürlichen Wissens die Frage an Bedeutung, wie die Glaubwürdigkeit der Artikel des Credo garantiert ist, die in einer als Wissenschaft im Sinne der Zweiten Analytik des Aristoteles konzipierten Theologie die Rolle der Prinzipien einnehmen, von denen aus systematische Ableitungen und Konklusionen erfolgen können. Die Zuverlässigkeit der wichtigsten Glaubensurkunde, nämlich der Heiligen Schrift, zumal des Neuen Testaments, bildet hier eine unersetzbare Voraussetzung im Sinne des antecedens ad fidem und wird auch aus diesem Grunde noch ernster als zuvor und von strikt ,realistischen“ Deutungsprämissen her verteidigt. ${ }^{85}$

4. Auffällig ist die häufiger zu beobachtende Verbindung der scholastischen Interpretation unserer Perikope mit den Debatten um die „Wahrheit“ in der Eucharistielehre. Die Sorge um die objektive Realität der verhüllten, sakramentalen Präsenz Christi im Altarsakrament, wie sie die berühmten Abendmahlstreitigkeiten des Mittelalters ebenso prägt wie die scholastischen Eucharistietraktate, findet ihre Entsprechungen in der Deutung jedes symbolischsakramentalen Handelns Christi, zumal in seiner österlich verklärten Leiblichkeit, das man gleichfalls von allem Schein des Irrealen zu befreien sucht. Dagegen tritt die bei Augustins „eucharistischer“ Deutung des Emmausgeschehens präsente ekklesiologische Dimension („Erkennen Christi“ im Kreis der das Herrenmahl feiernden Gemeinde) im Mittelalter eher in den Hintergrund.

5. Insgesamt deutet sich in unseren Texten ein verändertes Verständnis des „Sakramentalen“ an, das die scholastische Deutung der Heiligen Schrift und der Eucharistie gleichermaßen betrifft. Wie als Träger der sakramentalen Letztintention (res sacramenti) nicht mehr das Zeichen als solches (sacramentum tantum), sondern eine ontisch-objektive Zwischenwirkung (res et sacramentum) angenommen wird, so müssen auch alle zeichenhaften, mit einem geistlichen Ziel vollzogenen Handlungen Gottes, wie sie die Schrift berichtet, von einer in sich widerspruchsfrei identifizierbaren Handlungswirklichkeit getragen werden, um unbestreitbar „wahr“ zu sein. Wo immer „Sakramentalität“ zu finden ist, so die deutliche Tendenz im scholastischen Denken des Hochmittelalters, ist sie als ontisch gegründetes und mediatisiertes Geschehen zu explizieren.

Dr. Thomas Marschler

Ruhr-Universität Bochum

Katholisch-theologische Fakultät

GA $7 / 34$

D-44780 Bochum

84 Vgl. Ulrich Köpf, Die Anfänge der theologischen Wissenschaftstheorie im 13. Jahrhundert (Beiträge zur historischen Theologie 49). Tübingen 1974.

85 Vgl. Albert Lang, Die theologische Prinzipienlehre der mittelalterlichen Scholastik. Freiburg, Basel, Wien 1964, S. $154-155,207-208$. 